\title{
The effects of long intertrial intervals in probability learning
}

\author{
ARTHUR S. REBER AND T. A. NOSANCHUK \\ UNIVERSITY OF BRITISH COLUMBLA
}

The effects of past outcomes on prediction responses were investigated by comparing massed trials $110 \mathrm{sec}$ intertrial interval) with widely spaced trials (48-72 $h$ intertrial interval). Event-response and response-response dependencies were found with massed trials but not with spaced. It was argued that the lack of predictive power of independence-of-path models of probability learning (cf., Rose \& Vitz, 1966) could be due to the use of massed trials in traditional probability learning experiments.

One assumption common to many models of probabllity learning (PL) is independence-of-path (Bush \& Mostellar, 1955; Friedman, Burke, Cole, Keller, Millward, \& Estes, 1964; Estes, 1964). Phenomena such as negaHive recency (Jarvik, 1951) and the ability of Ss to respond appropriately to one-trial-dependencies in the event sequence (Anderson, 1960) render this assumption suspect. Other investigations of PL have weakened the independence-of-path assumption and introduced models which allow Ss a memory of past events which can influence prediction responses (Restle, 1961, Ch. 6; Burke \& Estes, 1957). While the success of these latter models (see Rose \& Vitz, 1966) argues against the independence-of-path assumption it is quite likely that the lack of independence is related to the experimental situation and is not necessarily intrinsic to PL.

In the traditional PL experiment trials are run at a fairly rapid rate, usually about one every 5 sec. If, using Estes' original conception of PL, Ss are sampling stimulus elements on each trial, it is likely that the sampling is not random but favors stimulus traces from more recent trials. The test of this "artificial" trialdependence would be to run a PL experiment with extremely long intertrial intervals. Information concerning the effects of spacing of trials is sparse. Most studies have been concerned with the effects of intertrial intervals on acquisition and asymptotic level (Grant, Hornseth, \& Hake, 1950) and have not used intervals beyond $30 \mathrm{sec}$. Since the interest here is on trial dependencies and not necessarily on acquisition or asymptotic responding, we designed a simple experiment where the "learning" of the probabllities of the several events would be superfluous.

\section{Method}

Ss were required to predict which of two events would occur on each of a series of trials, specifically whether a coin would come up heads or tails. There were a total of 13 trials; one trial on each of five separate days and four trials on the sixth and seventh days. The Ss were students in an introductory psychology course and the experiment was conducted during the first few minutes of each of seven successive class days. The intertrial interval for the spaced trials was then elther 48 or $72 \mathrm{~h}$; for the massed trials it was about $10 \mathrm{sec}$. Since the outcomes in coin tossing have a priori probabilities already associated with them and since most Ss have presumably had considerable prior experience with predicting such events, we favored it over the usual procedure of having Ss guess which of two lights will come on. Further, the use of a discrete physical event such as a coin toss should emphasize the independence of successive events. Admittedly, this procedure introduces a blas favoring independence that is not found in the traditional PL experiments where the events seemingly occur at the discretion of the E (Feldman, 1963). However, as will be seen below, even this was not sufficient to produce independence when trials were massed.

The number of $\mathrm{Ss}$ run each day differed owing to absenteeism and varied from 72 to 113 ; all results are thus given in proportions.

\section{Results and Discussion}

Table 1 gives the basic data. With spaced trials the probabillty of a "head" prediction $\left(\mathrm{P}_{\mathrm{h}}\right)$ is seemingly not sensitive to the trial-by-trial outcomes; runs of two heads and two tails failed to produce differential effects. On days where four massed trials were run however, the effects were quite different. Here a run of two head outcomes produced a sharp drop in the probability of predicting a head down to .360 , and a run of two talls increased $P_{h}$ to .700 .

Table 2 gives the Individual response sequences for the four trial sequences of Days 6 and 7 (the only trials for which this information is avallable). The "predicted" values were generated using $\mathbf{. 5 4 4}$ for the probability of a "head" outcome rather than the a priori .500. The value .544 corresponds to the average $P_{h}$ observed on the two days of massed trials weighted for the number of Ss run on each day. These data reveal strong response-response dependencies. A Kolmogoroff-Smirnor test showed a significant difference

\begin{tabular}{cccccc}
\multicolumn{2}{r}{ Table 1 } & \multicolumn{2}{c}{ Proportion of "heads" responses $\left(\mathbf{P}_{\mathbf{h}}\right)$ on each trial } \\
\hline $\begin{array}{c}\text { Spaced trials } \\
\text { (Days 1-5) }\end{array}$ & \multicolumn{3}{c}{$\begin{array}{c}\text { Massed trials } \\
\text { (Day 6) }\end{array}$} & \multicolumn{3}{c}{$\begin{array}{c}\text { Massed trials } \\
\text { (Day 7) }\end{array}$} \\
\hline Outcome & $\mathbf{P}_{\mathrm{h}}$ & Outcome & $\mathbf{P}_{\mathbf{h}}$ & Outcome & $\mathbf{P}_{\mathbf{h}}$ \\
$\mathrm{T}$ & .657 & $\mathrm{H}$ & .596 & $\mathrm{H}$ & .590 \\
$\mathrm{~T}$ & .565 & $\mathrm{H}$ & .528 & $\mathrm{~T}$ & .420 \\
$\mathrm{H}$ & .597 & $\mathrm{~T}$ & .360 & $\mathrm{~T}$ & .520 \\
$\mathrm{H}$ & .605 & $\mathrm{~T}$ & .629 & $\mathrm{~T}$ & .700 \\
$\mathrm{~T}$ & .606 & & & & \\
\hline
\end{tabular}


Table 2 Proportions of the several response sequences on the massed trials. Predicted proportions obtained by using $P_{h}=.544$ and assuming independence of responses.

\begin{tabular}{llllll}
\hline Sequence & Pred. & Obs. & Sequence & Pred. & Obs. \\
TTTT & .043 & .111 & HTHT & .062 & .042 \\
TTTH & .052 & .090 & HHTT & .062 & .048 \\
TTHT & .052 & .037 & HTTH & .062 & .106 \\
THTT & .052 & .026 & THHH & .073 & .016 \\
HTTT & .052 & .042 & HTHH & .073 & .026 \\
TTHH & .062 & .074 & HHTH & .073 & .106 \\
THTH & .062 & .032 & HHHT & .073 & .026 \\
THHT & .062 & .026 & HHHH & .088 & .190 \\
\hline
\end{tabular}

between the predicted and the observed proportions $(D=.107, p<.05)$.

It would seem rather clear that in the standard PL experiment with closely spaced trials the stimulus for each trial consists of recognizable traces from earlier trials and these traces are important in determining future predictions. Trial-by-trial dependencies are due, at least in part, to the massed trial techniques of traditional PL experiments.

An additional point of interest in the data is the overall level of $P_{h}$. The objective probabilities for the two events are .50 and in most two-choice PL experiments Ss initially predict the two events equally frequently. There obviously exists a bias for predicting "heads" that has persisted in spite of a great deal of experience reinforcing equal probabilities. ${ }^{1}$ Nor has the experience of this experiment had any effect. On a day some four weeks later the Ss were again asked to predict the outcome of a coin toss. The $\mathrm{P}_{\mathrm{h}}$ observed was .636, a value very close to that observed on the very first day of the experiment. This bias for "heads" has been previously documented. Schelling (1960, Chap. 1) asked Ss to guess what another person would predict on a coin toss. In a sample of 42 he found 36 replies of "heads." The bias then is obviously well known, even by the Ss themselves. With respect to coin tossing probability learning has clearly not taken place.
The use of an outcome probability of .50 does present some problems not encountered when one event is more likely than the other. Specifically, there is no optimal strategy, no way that the S can increase the probability of a correct response beyond .50. This situation has not been extensively studied and little is known about the extended behavior patterns that occur when the probabilities of the several events are all .50 .

\section{References}

ANDERSON, N. H. Effects of first-order conditional probability in a two-choice learning situation. J. exp. Psychol, 1960, 59, 73-93.

BURKE, C. J., \& ESTES, W. K. A component model for stimulus variables in discrimination learning. Psychometrika, 1957, 22, 133-145.

BUSH, R. R., \& MOSTELLAR, F. Stochastic models for learning. New York: Wiley, 1955.

ESTES, W. K. Probability learning. In A. W. Malton (Ed.), Categories of human learning. New York: Academic Press, 1964. Pp. 84128.

FELDMAN, J. Stimulation of behavior in the binary choice experiment. In E. A. Feigenbaum \& J. Feldman (Eds.), Computers and thought. New York: McGraw-Hill, 1963. Pp. 329-346.

FRIEDMAN, M.P., BURKE, J.C., COLE, M., KELLER, L., MILLWARD R. B., \& ESTES, W. E. Two-choice behavior under extended training with shifting probabilities of reinforcement. In R. C. Atkinson (Ed.), Studies in mathematical psychology. Stanford: Stanford University Press, 1964. Pp. 250-316.

GRANT, D. A., HORNSETH, J. P., \& HAKE, H. W. The influence of intertrial interval on the Humphreys' 'random reinforcement' effect during the extinction of a verbal response. J. exp. Psychol., 1950, 40, 609-612.

JARVIK, M. E. Probability learning and a negative recency effect in the serial anticipation of alternative symbols. J. exp. Psychol., 1951, 41, 291-297.

RESTLE, F. The psychology of judgement and choice. New York: Wiley, 1961.

ROSE, R. M., \& VITZ, P. C. Role of runs in probability learning. J. exp. Psychol, 1966, 72, 751-760.

SCHELLING, T. C. The strategy of conflict. New York: Oxford University Press, 1960, Chap. 1.

\section{Note}

1. After the experiment was over each $S$ was asked to approximate the number of times in his life he had guessed (predicted) the outcome of a coin-toss-less than 10 , between 10 and 100 , over 100 . Thirty-four percent replied over $100,58 \%$ replied between 10 and 100 and only $8 \%$ replied less than 10 times. 